The aim of our study was to analyse a significance of tumour necrosis factor (TNF)- $\alpha$ promoter gene polymorphisms in relation to the HLA-DR locus in genetic predisposition to pemphigus. TNF- $\alpha$ gene polymorphisms in position -238 and -308 were identified using a modified polymerase chain reactionrestriction fragment length polymorphism method in 53 patients with pemphigus (38 with pemphigus vulgaris, 15 with pemphigus foliaceus) and 87 healthy controls. The HLA-DRB1 locus was typed using the polymerase chain reaction SSO method in all the patients and 152 population controls.

Carriers of the TNF- $\alpha$ polymorphic $-308 \mathrm{~A}$ allele were found to be more frequent in the pemphigus foliaceus group in comparison with the control group (odds ratio $(O R)=8.12 ; p=0.0005)$. A significant association between HLA-DRB1*04 $\quad$ (OR = 3.86; $p$ cor $=0.0001)$ and DRB1*14 $(\mathrm{OR}=8.4 ; \quad$ pcor $=$ 0.0001 ) and pemphigus vulgaris was found. In this group of patients a decreased frequency of HLADRB1 $* 7$ (OR $=0.08 ; p$ cor $=0.006)$ was also identified.

We have shown for the first time a positive association of TNF- $\alpha$ polymorphism in position -308 with pemphigus foliaceus.

Key words: Polymorphism tumour necrosis factor- $\alpha$, HLA class II, Pemphigus vulgaris, Pemphigus foliaceus, Polish population

\section{Tumour necrosis factor- $\alpha$ polymorphism as one of the complex inherited factors in pemphigus}

\author{
Jolanta Dorota Torzecka ${ }^{1, C A}$, Joanna Narbutt ${ }^{1}$, \\ Anna Sysa-Jedrzejowska ${ }^{1}$, Maciej Borowiec ${ }^{2}$, \\ Anetta Ptasinska², Grzegorz Woszczek ${ }^{2}$ and \\ Marek L. Kowalski
}

${ }^{1}$ Department of Dermatology and ${ }^{2}$ Department of Clinical Immunology and Allergy, Medical University of Lodz, Krzemieniecka 5, 94-017 Lodz, Poland

\author{
${ }^{\mathrm{CA}}$ Corresponding author \\ Tel/fax: +48426884565 \\ E-mail: torzecka@poczta.onet.pl
}

\section{Introduction}

Pemphigus is an autoimmune disease, clinically characterized by bullae and erosions on the skin and mucous membranes. The aetiopathogenesis of pemphigus is not fully elucidated; however, additionally to an autoimmunological background, certain environmental agents such as medications, ultraviolet irradiation, diet, and viral infections are regarded as triggering factors, especially in genetically susceptible individuals. Two major forms of pemphigus, pemphigus vulgaris (PV) and pemphigus foliaceus (PF), based on the clinical picture, histological and immunological examinations are distinguished. In PF patients circulating IgG autoantibodies are directed against desmoglein 1 (Dsg 1) solely, while in PV antibodies are detected against desmoglein 3 (Dsg 3) sometimes in combination with anti-Dsg 1.

Studies on immunogenetic background in pemphigus have so far focused on association between the disease and certain HLA antigens. We have not found any literature data analysing other genetic factors involved in immune response in pemphigus.

Tumour necrosis factor (TNF)- $\alpha$ is a proinflammatory cytokine that plays a key role in the pathogenesis of many infections and inflammatory diseases. The
TNF- $\alpha$ gene is located within the class III region of the human HLA locus and several studies have shown extensive linkage disequilibrium both within the TNF locus and HLA class I and II. Several polymorphisms in the TNF- $\alpha$ gene were found to be associated with various autoimmune disorders. Elevated levels of TNF- $\alpha$ mRNA and protein have been demonstrated in skin and sera of patients with pemphigus vulgaris. ${ }^{1,2}$ Additionally, TNF- $\alpha$ receptor-deficient mice demonstrated a decreased susceptibility to pemphigus development after passive transfer of IgG autoantibodies. ${ }^{1} \quad$ TNF- $\alpha$ gene polymorphism in pemphigus patients has not so far been studied.

Literature data highlight a strong association between the disease and HLA class II locus. Associations of HLA-DRB1*0402, DRB1*1401 and DQB1*0503 alleles with pemphigus vulgaris were reported in Jewish, non-Jewish and Japanese populations. ${ }^{3-6}$ Interestingly, it has been shown that autoreactive $\mathrm{T}$ cells from PV patients recognize certain Dsg 3 fragments in restriction to HLA-DRB1*0402 and DQB1*0503. ${ }^{7}$ Similarly, in PF patients associations with HLA-DRB1*04, DRB1*14 and DRB1*16 were identified, $^{8}$ and direct involvement of these HLA molecules in presentation of desmoglein 1 fragments was suggested.' There are many reports on HLA alleles profile in pemphigus in various populations 
(Spanish, French, Italian, etc.); however, studies including exclusively Polish patients have not so far been performed.

In order to analyse a significance of TNF- $\alpha$ gene polymorphism in genetic predisposition to pemphigus, we designed an association study in a group of patients with PV and PF in Polish population, genotyped for HLA-DRB1.

\section{Materials and methods}

Our study comprised 53 patients with pemphigus (38 with PV, 15 with PF), 26 males and 27 females, with a mean age of 53.9 years. In all the patients the diagnosis was confirmed by histological and immunological examinations (direct and indirect immunofluorescence tests).

Genomic DNA was extracted from peripheral blood cells using the 'Easy Blood DNA Prep' (A\&A Biotechnology, Gdynia, Poland). TNF- $\alpha$ gene polymorphisms in positions -238 and -308 were identified using the modified polymerase chain reaction (PCR)-restriction fragment length polymorphismamplification created restriction sites method ${ }^{10}$ in the patients and in 87 unrelated healthy individuals from the members of the organ donors' families. The 117 base pair PCR fragment was amplified using Taq Polymerase (Rapidozym, Berlin, Germany) and modified primers introducing the $\mathrm{NcO}$ I restriction site for $\mathrm{G}$ in position -308 and the Ava II restriction site for $\mathrm{G}$ in position -238 . After digestion the obtained fragments were detected in a $4 \%$ agarose gel, stained with ethidium bromide and visualized under ultraviolet illumination.

Molecular typing of groups of HLA-DRB alleles at a low-resolution level in the patients and 152 healthy unrelated individuals was carried out using the Dynal RELI SSO HLA-DRB Test (Dynal Biotech A.S.A., Oslo, Norway) set of 36 molecular probes. Polymorphic fragments (second exon) of genes DRB1, DRB3, DRB4 and DRB5 were amplified in PCR reaction: 35 cycles of $15 \mathrm{sec}$ at $95^{\circ} \mathrm{C}, 45 \mathrm{sec}$ at $60^{\circ} \mathrm{C}, 15 \mathrm{sec}$ at $72^{\circ} \mathrm{C}$ and $5 \mathrm{~min}$ at $72^{\circ} \mathrm{C}$, using Taq polymerase and PCR buffer (Rapidozym, Berlin, Germany). After denaturation the PCR products were hybridized in SSPE buffer at $50^{\circ} \mathrm{C}$ with a set of specific molecular probes coating nylon stripes. The reaction results were read using the system of horseradish streptavidinperoxidase. The results of typing were analysed using the Dynal RELI SSO Pattern Matching Program.

The study protocol was approved by the Ethics Committee of the Lodz Medical University. All subjects gave written informed consent before entering the study.

\section{Statistical analysis}

The frequencies of HLA-DRB and TNF- $\alpha$ polymorphic alleles in patients and controls were compared using the two-sided Fisher's exact test. The significance in the genotype frequency differences between patients and controls was evaluated using the $\chi^{2}$ (two degrees of freedom) test. Values of $p<$ 0.05 was considered statistically significant. To correct for incidental significance, the $p$ value was multiplied by the number of alleles compared ( $p$ cor). An odds ratio (OR) was calculated as the cross product in a $2 \times 2$ table within $95 \%$ confidence intervals $(95 \% \mathrm{CI})$.

\section{Results}

The distribution of polymorphism of TNF- $\alpha$ in positions -238 and -308 in PV and PF is presented in Table 1. Carriers of allele A in position -308 were found to be more frequent in patients with $\mathrm{PF}$ in comparison with the control group $(p=0.0005$, $\mathrm{OR}=8.12,95 \% \mathrm{CI}=2.34-28.1)$. The A-allele frequency was also higher in PF patients (40\%) versus controls $(13.2 \%) \quad(p=0.001, \quad \mathrm{OR}=4.79,95 \% \mathrm{CI}=$ 2.02-11.34). No significant differences in -308 TNF- $\alpha$ polymorphism distribution between the PV and the control groups were observed. TNF- $\alpha$ polymorphism in position -238 was not significantly associated with either PV or PF.

The results of HLA-DR analysis in PV and PF patients are presented in Table 2.

PV patients showed a statistically significant association with HLA-DRB1*04 $(\mathrm{OR}=3.86, \quad$ p cor $=$ $0.0001)$ and $\mathrm{DRB}^{*} 14 \quad(\mathrm{OR}=8.4, \quad p \mathrm{cor}=0.0001)$. Also in this group we found a statistically significant decreased frequency of HLA-DRB ${ }^{*} 07$ (OR $=0.08$, $p$ cor $=0.006$ ) when compared with the control group (Table 2). No statistically significant differences between frequencies of HLA-DR alleles in patients with PF and the control group were identified.

\section{Discussion}

TNF- $\alpha$ is one of the mediators involved in inflammatory processes. Its production can be regulated at the transcriptional, post-transcriptional and translational levels. Variability in the promoter and coding regions of the TNF- $\alpha$ gene may modulate the magnitude of its secretory response. The results of the in vivo studies demonstrated that PV-IgG autoantibodies induced TNF- $\alpha$ mRNA in the skin. Some authors found over expression of this cytokine in the lesions in the pemphigus patients and the correlation between its serum level and the disease activity. ${ }^{2}$ These observations suggest the role of this mediator in the devel- 
TNF- $\alpha$ polymorphism in pemphigus

Table 1. TNF- $\alpha$ polymorphism in patients with pemphigus vulgaris and foliaceus compared with the control group

\begin{tabular}{|c|c|c|c|c|c|c|c|c|}
\hline & \multicolumn{2}{|c|}{$\begin{array}{c}\text { Pemphigus } \\
\text { vulgaris }(n=38)\end{array}$} & \multicolumn{2}{|c|}{$\begin{array}{c}\text { Pemphigus } \\
\text { foliaceus }(n=15)\end{array}$} & \multicolumn{2}{|c|}{$\begin{array}{l}\text { Controls } \\
(n=87)\end{array}$} & \multicolumn{2}{|c|}{ Statistical analysis } \\
\hline & $n$ & $\%$ & $n$ & $\%$ & $n$ & $\%$ & PV versus controls & PF versus controls \\
\hline \multicolumn{9}{|c|}{-238 genotypes } \\
\hline GG & 37 & 97.4 & 13 & 86.5 & 83 & 95.4 & NS & NS \\
\hline $\mathrm{GA}$ & 1 & 2.6 & 1 & 6.75 & 4 & 4.5 & & \\
\hline AA & 0 & 0 & 1 & 6.75 & 0 & 0 & & \\
\hline G carriers & 37 & 97.4 & 13 & 86.5 & 83 & 95.4 & NS & NS \\
\hline A carriers & 1 & 2.6 & 2 & 13.5 & 0 & 0 & NS & NS \\
\hline-238 alleles & $n=76$ & & $n=30$ & & $n=174$ & & & \\
\hline G & 75 & 98.7 & 27 & 90 & 170 & 97.7 & NS & NS \\
\hline \multirow{2}{*}{\multicolumn{9}{|c|}{-308 genotypes }} \\
\hline & & & & & & & & \\
\hline GG & 33 & 86.9 & 4 & 26.7 & 65 & 74.7 & NS & $p=0.002$ \\
\hline GA & 4 & 10.5 & 10 & 66.7 & 21 & 24.1 & & \\
\hline $\mathrm{AA}$ & 1 & 2.6 & 1 & 6.6 & 1 & 1.2 & & \\
\hline G carriers & 33 & 86.9 & 4 & 26.7 & 65 & 74.7 & NS & $p=0.0005$ \\
\hline A carriers & 5 & 13.1 & 11 & 73.3 & 22 & 25.3 & NS & $\begin{array}{c}p=0.0005^{*}, \mathrm{OR}=8.12,95 \% \\
\mathrm{Cl}=2.34-28.1\end{array}$ \\
\hline-308 alleles & $n=76$ & & $n=30$ & & $n=174$ & & & \\
\hline G & 70 & 92.1 & 18 & 60 & 151 & 86.8 & NS & $p=0.001$ \\
\hline A & 6 & 7.9 & 12 & 40 & 23 & 13.2 & NS & $\begin{array}{c}p=0.001 *, \mathrm{OR}=4.79,95 \% \\
\mathrm{Cl}=2.02-11.34\end{array}$ \\
\hline
\end{tabular}

* Statistically significant. NS, non-statistically significant.

opment of pemphigus lesions by increasing epithelial damage.

We found a significant association of the TNF- $\alpha$ -308 A allele with PF and, interestingly, no such a relation in a group of patients with PV was observed. There was no significant association of pemphigus phenotypes with the polymorphism in position -238 as well. The group of PF patients is rather small, but most of our PF patients (11/15, 73\%) were carriers of at least one -308 A allele. At this stage the relevance of this association is difficult to explain. It might result from strong linkage disequilibrium between HLA and TNF- $\alpha$ loci. It has been reported that the TNF- $\alpha-308$ A allele is in linkage with the HLA-A1/B8/DR3 haplotype, ${ }^{11}$ but no such HLA association with PF has yet been identified, which makes this hypothesis less probable. Another possibility may be related to direct involvement of TNF- $\alpha$ in pathomechanism of PF. The TNF- $\alpha-308$ polymorphism has been shown to alter function and has been associated with a sixfold to seven-fold higher level of transcription of TNF- $\alpha .{ }^{12}$ Other studies, however, have failed to show any functional change associated with this polymorphism. ${ }^{13}$ In vivo studies have also shown conflicting results, with Chen et al. ${ }^{14}$ and Juszczynski et $a l .{ }^{15}$ finding high levels of TNF- $\alpha$ associated with the -308 G/A polymorphism, while others reported no significant association between -308 polymorphism and TNF- $\alpha$ levels. ${ }^{16}$ Thus, our preliminary observation of positive association between the TNF- $\alpha$ locus

Table 2. Frequency of HLA-DRB1 alleles in patients with pemphigus vulgaris and foliaceus compared with the control group

\begin{tabular}{|c|c|c|c|c|c|c|c|c|}
\hline \multirow[t]{2}{*}{ DRB1 } & \multicolumn{2}{|c|}{$\begin{array}{l}\text { Pemphigus } \\
\text { vulgaris }(n=76)\end{array}$} & \multicolumn{2}{|c|}{$\begin{array}{l}\text { Pemphigus } \\
\text { foliaceus }(n=30)\end{array}$} & \multicolumn{2}{|c|}{$\begin{array}{l}\text { Controls } \\
(n=304)\end{array}$} & \multicolumn{2}{|c|}{ Statistical analysis } \\
\hline & $n$ & $\%$ & $n$ & $\%$ & $n$ & $\%$ & PV versus controls & PF versus controls \\
\hline *01 & 8 & 10.5 & 7 & 23.3 & 31 & 10.2 & NS & NS \\
\hline * 15/16 & 5 & 6.6 & 2 & 6.7 & 51 & 16.8 & NS & NS \\
\hline *03 & 3 & 3.9 & 8 & 26.7 & 31 & 10.2 & NS & $p<0.01, p$ cor $=\mathrm{NS}$ \\
\hline$* 04$ & 27 & 35.5 & 5 & 16.7 & 38 & 12.5 & $\begin{aligned} p & <0.0001^{*}, p c o r=0.0001 \\
\mathrm{OR} & =3.86,95 \% \mathrm{Cl}=2.16-6.89\end{aligned}$ & NS \\
\hline *07 & 1 & 1.3 & 3 & 10 & 44 & 14.5 & $\begin{array}{c}p=0.0005^{*}, p \text { cor }=0.006 \\
\mathrm{OR}=0.08,95 \% \mathrm{Cl}=0.01-0.58\end{array}$ & NS \\
\hline *08 & 2 & 2.6 & 1 & 3.3 & 7 & 2.3 & NS & NS \\
\hline *09 & 2 & 2.6 & 0 & & 3 & 1 & NS & NS \\
\hline$* 10$ & 0 & & 0 & & 7 & 2.3 & NS & NS \\
\hline$* 11$ & 11 & 14.5 & 3 & 10 & 42 & 13.8 & NS & NS \\
\hline * 12 & 0 & & 0 & & 14 & 4.6 & NS & NS \\
\hline *13 & 6 & 79 & 1 & 3.3 & 30 & 9.9 & NS & NS \\
\hline$* 14$ & 11 & 14.5 & 0 & & 6 & 2 & $\begin{array}{c}p<0.0001^{*}, p c o r=0.0001 \\
\mathrm{OR}=8.4,95 \% \mathrm{Cl}=2.99-23.5\end{array}$ & NS \\
\hline
\end{tabular}

\footnotetext{
* Statistically significant. NS, non-statistically significant.
} 
and PF may suggest that TNF- $\alpha$ may be a cytokine directly involved in the pathomechanism of PF or may be related to differential clinical manifestation of various types of pemphigus. A similar role of the TNF- $\alpha$ polymorphism has been suggested in other autoimmune diseases like rheumatoid arthritis or systemic lupus erythematosus. ${ }^{17,18}$ Based on the presented data we conclude that TNF- $\alpha$ polymorphism is part of the complex inherited factors in pemphigus.

The role of the genetic background, including mainly HLA class II genes is strongly stressed in the pathogenesis of pemphigus. Many authors have shown that HLA-DR*04 and DR*14 confer strong susceptibility to PV in different ethnic groups: Jewish $^{3}$, non-Jewish ${ }^{4}$ and Japanese. ${ }^{5,6}$ Our studies conducted in Polish pemphigus patients confirmed these observations. The frequency of both HLA-DRB1*04 and DRB1*14 alleles were significantly higher in patients with PV than in an ethnically matched control group. Current evidence indicates that Dsg 3 is the dominant initial autoantigen in PV and that anti-Dsg 3 antibodies produced in restriction to HLADRB1*0402 and DQB1*0503 (in strong linkage disequilibrium with DRB1*1401) induce lesion formation. It has been shown that only antigen presenting cells expressing HLA-DRB1*0402 and DQB1*0503 were capable of presenting Dsg 3 to autoreactive Th1 and Th2 clones, stressing a direct involvement of particular HLA antigens in the pathomechanism of $\mathrm{PV}^{7}$

The relationship between PF and HLA class II locus is less clear. Lombardi et al ${ }^{19}$ and Miyagawa et al ${ }^{20}$ indicated that HLA-DRB1*04 and HLA-DRB1*14 are also associated with PF but in our study group we did not find such an association. In the case of the endemic form of PF (fogo selvagem), it has been shown that the autoimmune proliferative T-cell response is directed to external fragment of Dsg 1 in restriction to certain HLA alleles, mainly DRB1*0404, DRB1*1402, DRB1*1406 and DRB1*1602, which share the same sequence (LLEQRRAA) in the DRB hypervariable domain from amino acids 67 to $74 .^{9}$ The study performed by Moraes et $a l{ }^{8}$ in three different Brazilian populations with FS showed positive association with HLA-DRB1*01, DRB1*04 and DRB1*14, which suggests that a similar pathomechanism as in PV may apply to fogo selvagem and possibly to PF as well. The fact that presentation of causative autoantigens in PF may be restricted by several HLA alleles might explain lack of significant positive associations found in our study. Further studies on bigger groups with PF are required to demonstrate such associations with the HLA locus.

In accordance with an idea of direct presentation of pemphigus autoantigens by certain HLA alleles, a negative association of HLA with pemphigus may occur, related to insufficient presentation of these antigens in restriction to some other HLA alleles. The significantly decreased frequency of HLA-DRB1*07 observed in our patients, similar to the results of HLA analysis in Italian and Brazilian patients with PV and $\mathrm{PF}^{19,21}$ suggest its protective role against pemphigus development. Other studies have also shown that certain HLA alleles play a protective role; for example, in Spanish patients with PV (DRB1*13) ${ }^{22}$ and in Turkish patients (DR 11, DQ 7 and DQ 2). ${ }^{23}$

In conclusion, we have shown a positive association of TNF- $\alpha$ polymorphism in position -308 with $\mathrm{PF}$ for the first time. We also show that the same association of HLA-DR*04 and DR*14 alleles with PV, as reported before in other ethnic groups, is also present in Polish pemphigus patients. Although TNF$\alpha$ and HLA-DR genes may play a role in pemphigus development, the genetic association of TNF- $\alpha$ polymorphism with pemphigus seems to be independent of the HLA class II antigens.

ACKNOWLEDGEMENTS. The authors would like to thank Prof. M. Blaszczyk, Prof. C. Kowalewski, Prof. M. Dmochowski, Prof. W. Placek and Prof. B. Chodynicka for their help in collecting pemphigus patients blood samples. They also thank Dr H. H. Pas for the critical review. This work was supported by a grant (4P05B04919) from State Committee for Scientific Research.

\section{References}

1. Feliciani C, Toto P, Amerio P, Pour SM, Coscione G, Shivji G, Wang B, Sauder DN. In vitro and in vivo expression of interleukin-1alpha and tumor necrosis factor-alpha mRNA in pemphigus vulgaris: interleukin1alpha and tumor necrosis factor-alpha are involved in acantholysis. $J$ Invest Dermatol 2000; 114: 71-77.

2. D'Auria L, Bonifati C, Mussi A, et al. Cytokines in the sera of patients with pemphigus vulgaris: interleukin- 6 and tumor necrosis factor-alpha levels a significantly increased as compared to healthy subjects and correlate with disease activity. Eur Cytokine Network 1997; 4: 383-387.

3. Ahmed AR, Yunis EJ, Khatri K. Major histocompatibility complex haplotype studies in Ashkenazi Jewish patients with pemphigus vulgaris. Proc Natl Acad Sci USA 1990; 87: 7658-7662.

4. Ahmed AR, Wagner R, Khatri K. Major histocompatibility complex haplotypes and class II genes in non-Jewish patients with pemphigus vulgaris. Proc Natl Acad Sci USA 1991; 88: 5056-5061.

5. Niizeki $\mathrm{H}$, Inoko $\mathrm{H}$, Mizuki $\mathrm{N}$, Inamoto $\mathrm{N}$, Watababe $\mathrm{K}$, Hashimoto $\mathrm{T}$, Nishikawa T. HLA-DQA1, -DQB1 and -DRB1 genotyping in Japanese pemphigus vulgaris patients by the PCR-RFLP method. Tissue Antigens 1994; 44: $248-251$

6. Miyagawa S, Higashimine I, Iida T, Yamashina Y, Fukumoto T, Shirai T. HLA-DRB1*04 and DRB1*14 alleles are associated with susceptibility to pemphigus among Japanese. J Invest Dermatol 1997; 109: 615-618.

7. Veldman C, Stauber A, Wassmuth R, Uter W, Schuler G, Hertl M. Dichotomy of autoreactive Th1 and Th2 cell responses to desmoglein 3 in patients with pemphigus vulgaris (PV) and healthy carriers of PVassociated HLA class II alleles. I Immunol 2003; 170: 635-642.

8. Moraes ME, Fernandez-Vina M, Lazaro A, et al. An epitope in the third hypervariable region of the DRB1 gene is involved in the susceptibility to endemic pemphigus foliaceus (fogo selvagem) in three different Brazilian populations. Tissue Antigens 1997; 49: 35-40.

9. Lin MS, Fu CL, Aoki V, et al. Desmoglein-1-specific T lymphocytes from patients with endemic pemphigus foliaceus (fogo selvagem). J Clin Invest 2000; 105: 207-213.

10. Vinasco J, Beraun Y, Nieto A, Fraile A, Mataran L, Pareja E, Martin J. Polymorphism at the TNF loci in rheumatoid arthritis. Tissue Antigens 1997; 49: 74-78.

11. Wilson AG, de Vries N, Pociot F, di Giovine FS, van der Putte LB, Duff $\mathrm{GW}$. An allelic polymorphism within the human tumor necrosis factor alpha promoter region is strongly associated with HLA A1, B8, and DR3 alleles. J Exp Med 1993; 177: 557-560.

12. Wilson AG, Symons JA, McDowell TL, McDevitt HO, Duff GW. Effects of a polymorphism in the human tumor necrosis factor alpha promoter on transcriptional activation. Proc Natl Acad Sci USA 1997; 94: 3195-3199.

13. Brinkman BM, Zuijdeest D, Kaijzel EL, Breedveld FC, Verweij CL Relevance of the tumor necrosis factor alpha (TNF alpha) -308 
promoter polymorphism in TNF alpha gene regulation. J Inflamm 2002; 46: $32-41$

14. Chen G, Wilson R, Wang SH, Zheng HZ, Walker JJ, McKillop JH. Tumour necrosis factor-alpha (TNF-alpha) gene polymorphism and expression in pre-eclampsia. Clin Exp Immunol 1996; 104: 154-159.

15. Juszczynski $\mathrm{P}$, Kalinka E, Bienvenu J, et al. Human leukocyte antigen class II and tumor necrosis factor genetic polymorphisms are independent predictors of non-Hodgkin lymphoma outcome. Blood 2002; 100: 3037-3040.

16. Pociot F, Wilson AG, Nerup J, Duff GW. No independent association between a tumor necrosis factor-alpha promotor region polymorphism and insulin-dependent diabetes mellitus. Eur I Immunol 1993; 23 3050-3053.

17. Fabris M, Tolusso B, Di Poi E, Assaloni R, Sinigaglia L, Ferraccioli G. Tumor necrosis factor-alpha receptor II polymorphism in patients from southern Europe with mild-moderate and severe rheumatoid arthritis. $J$ Rheumatol 2002; 29: 1847-1850.

18. Zuniga J, Vargas-Alarcon G, Hernandez-Pacheco G, Portal-Celhay C, Yamamoto-Furusho JK, Granados J. Tumor necrosis factor-alpha promoter polymorphisms in Mexican patients with systemic lupus erythematosus (SLE). Genes Immun 2001; 2: 363-366.
19. Lombardi ML, Mercuro O, Ruocco V, et al. Common human leukocyte antigen alleles in pemphigus vulgaris and pemphigus foliaceus Italian patients. J Invest Dermatol 1999; 113: 107-110.

20. Miyagawa S, Amagai M, Niizeki H, et al. HLA-DRB1 polymorphisms and autoimmune responses to desmogleins in Japanese patients with pemphigus. Tissue Antigens 1999; 54: 333-340.

21. Petzl-Erler ML, Santamaria J. Are HLA class II genes controlling susceptibility and resistance to Brazilian pemphigus foliaceus (fogo selvagem)? Tissue Antigens 1989; 33: 408-414.

22. Gonzalez-Escribano MF, Jimenez G, Walter K, et al. Distribution of HLA alleles among Spanish patients with pemphigus vulgaris. Tissue Antigens 1998; 52: $275-278$

23. Birol A, Anadolu RY, Tutkak H, Gurgey E. HLA-class 1 and class 2 antigens in Turkish patients with pemphigus. Int J Dermatol 2002; 41: $79-83$

Received 22 July 2003

Accepted 25 August 2003 


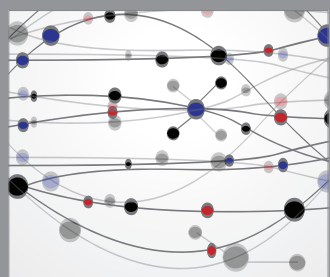

The Scientific World Journal
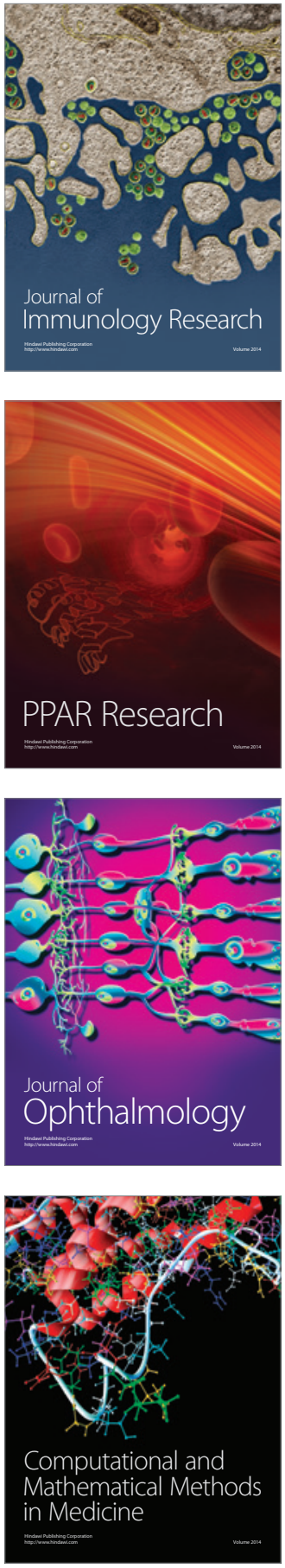

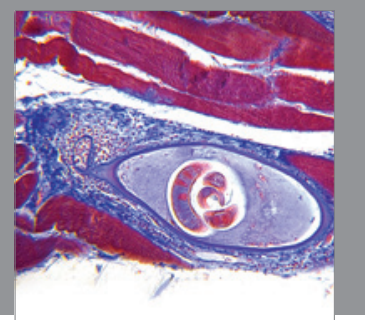

Gastroenterology

Research and Practice
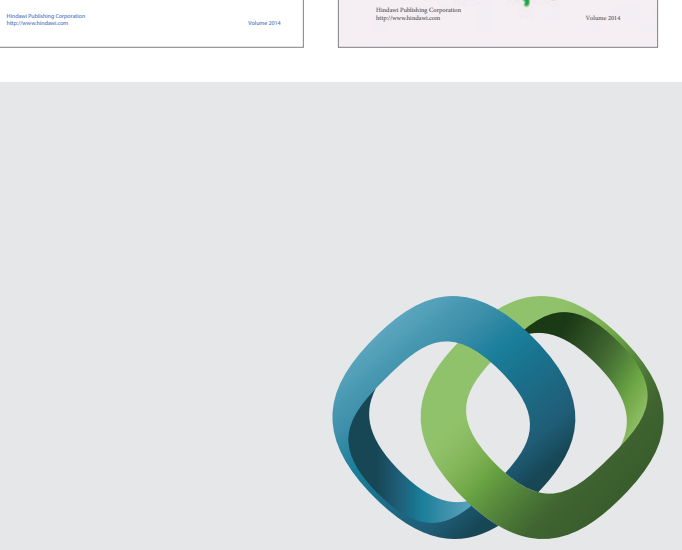

\section{Hindawi}

Submit your manuscripts at

http://www.hindawi.com
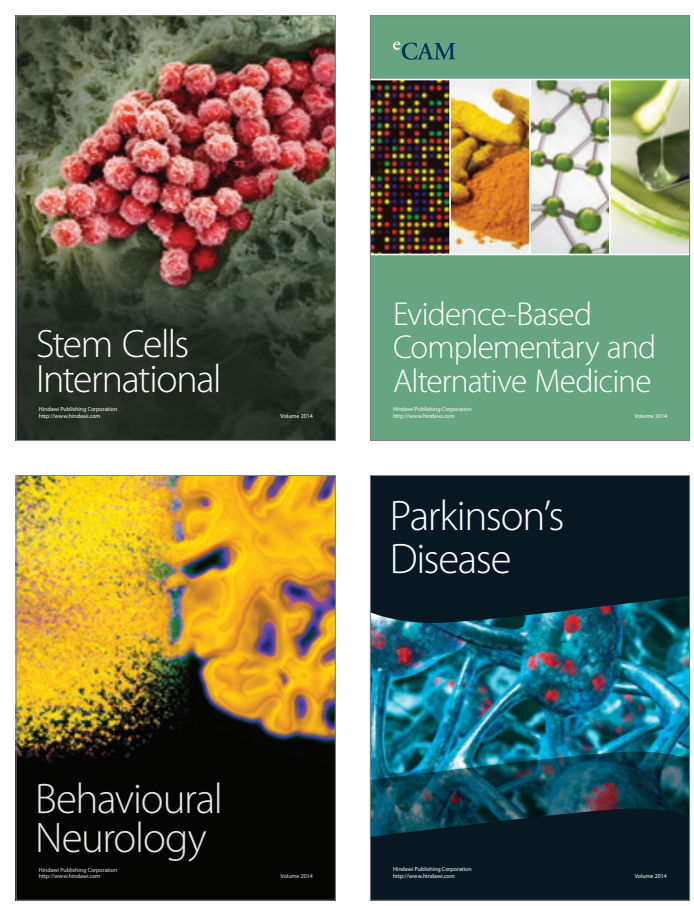

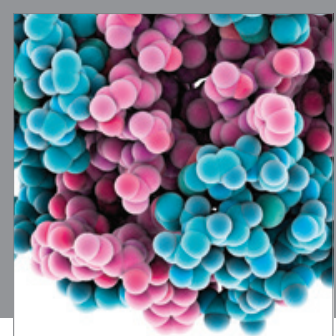

Journal of
Diabetes Research

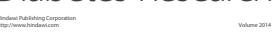

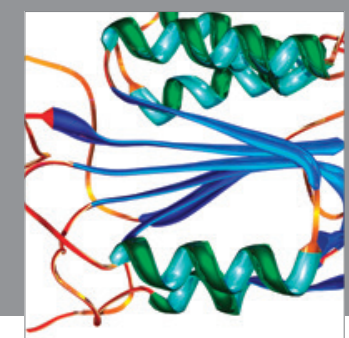

Disease Markers
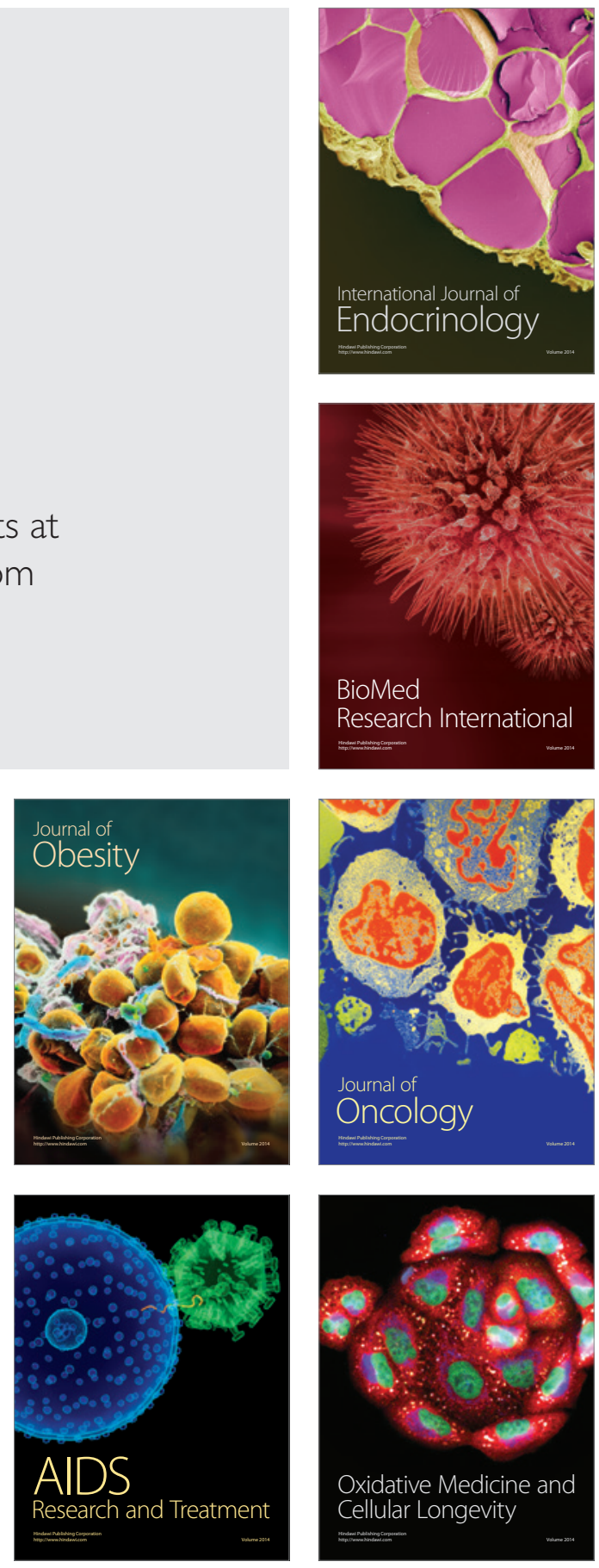